\title{
Analysis of Dynamic Inertia Forces at Main Bearing of Ship Reciprocating Engines
}

\author{
A. Zubaydi ${ }^{1}$, M. Ariana ${ }^{1}$, L. Baliwangi ${ }^{1}$, A. A. Masroeri ${ }^{1}$, F. Louhenapessy ${ }^{2}$, M. Tukan ${ }^{2}$, and S. M. \\ Taribuka $^{2}$
}

\begin{abstract}
During operation, a ship reciprocating engine will vibrate due to the force resulting from the cycle movement of the dynamic components. Soon or later, the vibration will cause wear of engine components. Therefore, the cause of vibration should be early identified so that the propagation of wear can be anticipated. The study modeled the ship reciprocating engine as a two stroke engine, and analyzed one of the causes of the engine vibration, i.e. the force acting on main bearing, using a numerical simulation. An experimental study was also carried out for measuring the acceleration of vibration response due to the numerical dynamic inertia force. The results showed that the dynamic inertia force acting on the main bearing is the main cause of the vibration of engine.
\end{abstract}

Keywords-acceleration, dynamic inertia force, engine, main bearing, vibration

\section{INTRODUCTION}

The main component required for constructing the engine including the ship reciprocating engine are piston, connecting rod, crankshaft, cylinder, and engine block. During the operation of ship reciprocating engine, the piston moves translatively and the crankshaft moves rotatively; furthermore, the connecting rod that has function to connect piston and crankshaft, more variably, translatively or rotatively.

Therefore, the magnitude of dynamic inertia force cannot be measured since the components are inside the engine and they move rotatively; as a result a numerical approach is needed. For these reasons, some researchers developed physical and mathematical models of the dynamic inertia forces of some engine components.

Astashev et. al. . created mathematical modeling for the construction of two stroke engine [1]. It is stated that the total of inertia moment of engine components is equivalent to the amount of each component of the mechanism of engine moment.

Cho et. al. made mathematical model of collision between piston and cylinder. It is foundout that dynamic inertia force has caused to the occurrence of collisions between piston and cylinder. Furthermore, the dynamic inertia force of piston in horizontal and vertical directions can be determined using mass and acceleration of joint piston [2].

Inagaki et. al.. developed mathematical modeling for obtaining dynamic inertia and friction forces between piston and cylinder. It is reported that the magnitudes of

${ }^{1}$ A. Zubaydi, M. Ariana, L. Baliwangi, A. A. Masroeri are with Department of Marine Engineering, FTK, Institut Teknologi Sepuluh Nopember, Surabaya, 60111, Indonesia. E-mail: zubaydi@na.its.ac.id

${ }^{2}$ F. Louhenapessy, M. Tukan, S. M. Taribuka are with Faculty of Engineering, Universitas Pattimura, Ambon, 97233, Indonesia. E-mail: frans@na.its.ac.id dynamic inertia force from the side and the friction force between piston cylinder are the multiplication of acceleration and mass of piston with connecting rod.

Tugiman [4] carried out investigations on a single cylinder of combustion engine. The conclusion derived from his research was that the dynamic inertia force on engine without the unbalanced weight appeared on the crankshaft. Meanwhile, the smallest dynamic inertia force reacted on the cylinder wall.

Chen et. al.. [5] have modeled the vibration engine. It was found from the results that the noise and vibration of engine were produced by the combustion pressure and the dynamic inertia force. They caused frictions between: (a) piston and cylinder, (b) crankshaft and main bearing.

Based on the above results, the purpose of this research is to analyze dynamic inertia force produced by other dynamic components of engine. The dynamic inertia force was simulated by using the numerical equations, and the results were then utilized as input to vibrate engine in the experimental study.

\section{THEORETICAL BACKGROUND}

\section{A. Mathematical Formulation}

As pointed out in the introduction, the magnitude of dynamic inertia force cannot be measured since the components are inside the engine. Therefore, the components of dynamic inertia force acting on the main bearing during the operation of engine are investigated numerically, and the results are formulated in mathematical equations.

Fig 1.a shows dynamic components of engine such as crank web (2), connecting rod (3), piston (4) and main bearing $\left(\mathrm{O}_{2}\right)$, whereas Fig 1.b draws their amplitude diagram.

It can be seen from Fig 1.b that the force working at point $\mathrm{O}_{2}$ of main bearing can be found by calculating the acceleration of piston component $\mathrm{a}_{\mathrm{t}}$ and connecting rod $\mathrm{a}_{\mathrm{cg}}$ at point $\mathrm{C}_{\mathrm{g}}$ with angular velocity crank web $\omega_{2}$.

1. Acceleration of Piston

Fig 1.a shows that $r_{b}$ is the distance between point B and supporting point $\mathrm{O}_{2}$. Therefore, the acceleration of $\mathrm{r}_{b}$ can be expressed as the addition of $r_{2}$ and $r_{3}$ which have fixed length and function of the slider position as shown in (1):

$$
\begin{aligned}
\ddot{r}_{b}= & -r_{2} \omega_{2}^{2} \cos \theta_{2}-r_{3} \omega_{3}^{2} \cos \theta_{3} \\
& -r_{3}\left(\frac{r_{2} \omega_{2}^{2} \sin \theta_{2}+r_{3} \omega_{3}^{2} \sin \theta_{3}}{r_{3} \cos \theta_{3}}\right) \sin \theta_{3}
\end{aligned}
$$

Equation above is the acceleration of piston in the vertical direction. The acceleration of piston in the horizontal direction is ignored since there is no force acting on the wall of cylinder. 


\section{Accelerations of Connecting Rod}

Based on the diagram in Fig 1.b, vector model of $r_{c g}$ is created in Fig 2, and the result is utilized for analyzing the value of the acceleration of connecting rod.

The value of $r_{c g}$ is the summation of the radius of web $r_{2}$ with the length from point $\mathrm{A}$ to the centre of connecting $\operatorname{rod}$ mass $r_{d}$, in which the result is given as:

$\vec{r}_{c g}=\vec{r}_{2}+\vec{r}_{d}=r_{2} e^{i \theta_{2}}+r_{d} e^{i \theta_{3}}$

From (2), the acceleration equation of connecting rod is found as follow:

$$
\left|a_{c g}(t)\right|=\sqrt{\left\{a_{c g}(t)\right\}^{2}+\left\{b_{c g}(t)\right\}^{2}}
$$

where

$a_{c g}(t)=\left[-r_{2} \omega_{2}^{2} \cos \theta_{2}(t)-r_{d} \alpha_{3}(t) \sin \theta_{3}(t)-r_{d} \omega_{3}^{2}(t) \cos \theta_{3}(t)\right]$

and

$b_{c g}(t)=\left[-r_{2} \omega_{2}^{2} \sin \theta_{2}(t)+r_{d} \alpha_{3}(t) \cos \theta_{3}(t)-r_{d} \omega_{3}^{2}(t) \sin \theta_{3}(t)\right]$

Next, the value of angle $\Theta_{\mathrm{cg}}$ of $r_{\mathrm{cg}}$ can be determined from (4) and (5) as shown in (6):

$$
\theta_{c g}(t)=\tan ^{-1}\left(\frac{b_{c g}}{a_{c g}}\right)
$$

\section{B. Inertia Forces}

\section{Inertia Forces of Piston}

When the piston moves translatively in the cylinder, the equation of inertia force is as follow:

$$
F_{4}=m_{p} a_{t}
$$

where $a_{t}=\ddot{r}_{b}$ is the acceleration of piston obtained from (1).

\section{Inertia Force of Connecting Rod}

The part of connecting rod connected to joint piston moves translatively in the cylinder, whereas the part of connecting rod connected to joint crank pin moves rotatively. The equation of inertia force produced by the connecting rod component is shown in (8):

$$
F_{3}=m_{c r} a_{c g}
$$

where $\mathrm{a}_{\mathrm{cg}}$ is the acceleration of connecting rod obtained from (3).

3. Inertia Forces of Main Bearing

The forces acting on main bearing are modeled in Fig 3. $a$ and showed the acceleration $\mathrm{a}_{\mathrm{t}}$ and force $\mathrm{F}_{4}$ of piston accompanying their directions. It can be seen from Fig 3.a that the tangential and normal accelerations are located at the same axes as the point $\mathrm{C}_{\mathrm{g}}$ at the connecting rod.

The sequence of forces acting on the engine components can be seen in the free body diagram in Fig 3.b. It can be constructed from Fig 3.b that the equilibrium of force for determining the value of contact is forced with a small angle $\beta_{1}$ in main bearing at point 0 as shown in (9) and (10):

$F_{32}=\sqrt{\left\{R\left(\vec{F}_{32}\right)\right\}^{2}+\left\{I\left(\vec{F}_{32}\right)\right\}^{2}}$

and

$$
\beta_{32}=\tan ^{-1} \frac{I\left(\vec{F}_{32}\right)}{R\left(\vec{F}_{32}\right)}
$$

The force $F_{32}$ in (9) is a complex number with the angle $\beta_{32}$ of (10) and is at the connection point of crank pin. The force $\mathrm{F}_{32}$ can be calculated using (11):

$$
\vec{F}_{32}=F_{3}+F_{4}
$$

The force in (11) works at the crank pin in which the values of $F_{3}$ and $F_{4}$ are found from (7) and (8). Next, Fig 3.b shows that the equation of force on main bearing, $F_{12}$ has the same magnitude as the force $F_{32}$, but in the opposite direction. Therefore, the force $F_{12}$ can be determined using (12):

$F_{12}=\left|F_{23}\right|=F_{32}$

where

$F_{12 x}=F_{32} \sin \left(\pi-\beta_{1}\right)$

$F_{12 y}=F_{12} \cos \left(\pi-\beta_{1}\right)$

and

$\beta_{1}=\beta_{32} \pm \pi\left(+\right.$ if $\beta_{32}\langle\pi$ and vise versa $)$

$\mathrm{F}_{12 \mathrm{x}}$ works in the horizontal axis (imaginary axis) while $F_{12 y}$ works in the vertical axis (real axis). This force is the unbalanced force acting on the engine. The (15) shows the angle formed by $\mathrm{F}_{12}$ with the real axis.

4. Inertia Forces due to Weight of Crankshaft System

In order to get the inertia force due to the weight of crankshaft system components, i.e. the gravitational force, working on the main bearing at the supporting point, the weight of crankshaft system components are modeled in Fig 4.

The modeling of components that consists of shaft, web, and flywheel is needed since these forces always exist in static or dynamic conditions.

The gravitational force of each components of crankshaft system can be calculated using (16):

$G_{t}=m_{t} g$

in which the number of gravitational forces depend on the number of the dynamic components.

The gravitational forces of the crankshaft, web, and flywheel work at the supporting point $\mathrm{Q}$ and cause the appearance of the reaction force $\mathrm{F}_{\mathrm{R} 1}$ as shown in (17):

$$
G_{R G}(e+a)+G_{s}\left(e-x_{o}\right)+G_{D}(e-b)+G_{p e}(e-c)+G_{D}(e-d)
$$

$F_{R 1}=\frac{+G_{2}\left(x_{1}\right)}{}$

where e is obtained using (18) which is the development of the Giancarlo Genta Equation [6] as follow:

$$
\begin{aligned}
e= & 2 c+\frac{\left(a+0.15 D\left(D^{4}\right)\right)}{D^{\prime 4}}+\left[2 b-0.15\left(D+D^{\prime}\right)\right] \frac{D^{4}}{d_{w}{ }^{4}} \\
& +r\left(0.065 \frac{D}{b}+0.58\right) \frac{D^{4}}{b d_{w}{ }^{3}}+0.16 \frac{D^{4}}{b^{2} d_{w}}+0.15 D
\end{aligned}
$$

In the dynamic condition, i.e. during the working of engine, the reaction force in (17) becomes the inertia force of crankshaft system.

5. Inertia Force due to Working of Crankshaft System

Fig. 5 shows the model of crankshaft system. The system consists of crank web (2) and flywheel (3) and has the shaping of disc. They are installed on the same shaft so that they have the same angular velocity. When the shaft is rotated, the crank web and flywheel are also rotated.

The dynamic inertia forces for both discs can be determined by calculating the torque of crank web and flywheel that work on the main bearing and centered at point Q as shown in (19):

$F_{d}=\frac{\tau_{d}}{e}$ 


\section{Vibrations of Engine}

While in progress, the engine vibrates because of the inertia force cycle of dynamic components. The vibration of engine can be modeled using the general equation for a Multiple Degree of Freedom (MDOF) system as follow: $[M]\{\ddot{x}(t)\}+[C]\{\dot{x}(t)\}+[K]\} x(t)\}=\{F(t)\}$

Equation above is used for determining the level of amplitude in the form acceleration of vibration of engine.

\section{Model Engine}

In order to know the effect of the dynamic inertia force causing the appearance of vibration acceleration of engine, the engine is modeled using two stroke engine as shown in Fig 6.

The engine has a single cylinder with the power of 5 $\mathrm{HP}$ and the rpm of 500. The choice of engine type is due to the number of dynamic components is less than the four stroke engine so that the more accurate results can be obtained in validating the signal of experiment measurements.

\section{METHOD}

The experiment was conducted to measure the acceleration amplitude of vibration in the time and frequency domains due to dynamic inertia forces working on the main bearing, which is unbalanced, accumulated, and cycled in horizontal and vertical directions.

Therefore, the experimental setup and the schematic of measurement of the engine vibration were designed in Fig 7. The engine body around the crankshaft is assumed to be the bearing house because there is the main bearing supporting crankshaft at that place.

The accelerometer is mountained at supporting point $\mathrm{Q}$ and used to measure the vibration response in vertical and horizontal directions, while the converter is used to adjust the rotation engine by changing the rotation motor. The optical key phasor is used as a pulse generator during the progress of vibration measurement.

Furthermore, the charge amplifier is utilized to condition the measurement of vibration signal by the accelerometer. The function of MSA (Multi Signal Analyzer) is to process the measurement signals for obtaining the waveform and frequency spectrum. The results are in the form of vibration response signals.

During the experiment, the engine is off and rotated using AC motor so that the air can be in and out because of the spark that is open. As a consequence, there is no force coming from the air compression, combustion, and expansion. Therefore, the dynamic inertia force is dominant.

The measurement of acceleration amplitude of vibration was taken at the position of web $0^{\circ}$, when the piston reached top dead point in vertical direction, and at position of web $90^{\circ}$ in horizontal direction when the position of the exhaust door starts to open.

\section{RESULT AND DISCUSSION}

\section{A. Acceleration of Piston}

The result of piston acceleration calculated by (1) is drawn in Fig. 8 and shows the graph of acceleration of the piston to the crankshaft position.
Fig. 8 indicates that the graph of the acceleration of piston is not a pure cosine.

This is due to the acceleration of piston is a joint movement between the web and connecting rod in which the movement of the web follows the cosine rule, while the movement of connecting rod follows the sine rule. The maximum value of piston acceleration is $170 \mathrm{~m} / \mathrm{sec}^{2}$ on positive region, while in the negative region the value of piston acceleration reaches $293 \mathrm{~m} / \mathrm{sec}^{2}$.

Furthermore, the graph also demonstrates that in one round of the crankshaft, the piston moves twice, vertically up and down, so that the inertia force of piston and connecting rod concentrated at the crank pin will experience fluctuations.

\section{B. Acceleration of Connecting Rod}

The calculation of (2) for the acceleration of a connecting rod which is the resultant acceleration of the normal and tangential directions can be seen in Fig. 9. From Fig. 9, it can be shown the relationship between the acceleration of connecting rod to the rotation of crankshaft, where the movement of the web in one turn leads to changes in angle of the acceleration of $\mathrm{C}_{\mathrm{g}}$. The maximum acceleration is $260 \mathrm{~m} / \mathrm{sec}^{2}$, whereas the minimum acceleration is $121 \mathrm{~m} / \mathrm{sec}^{2}$.

In addition, Fig. 9 states that the connecting rod moves four times in one round of the crankshaft in which the position of connecting rod changes in each phase of $90^{\circ}$. At position 0 to $90^{\circ}$, the acceleration is equal to at the position $270^{\circ}$ to $360^{\circ}$, whereas in the position $90^{\circ}$ to $180^{\circ}$, the acceleration is equal to the position from $180^{\circ}$ to $270^{\circ}$.

\section{Inertia Force of Piston}

The result of the inertia force of piston calculated by (6) is shown in Fig. 10 and shows the relationship between the inertia forces of the piston against the crankshaft position. The maximum force is $35 \mathrm{~N}$ in the positive area and $59 \mathrm{~N}$ is in the negative region. Fig 10 also indicates that the load of piston fluctuates and its direction follows the acceleration of piston and the rotation of crankshaft.

\section{Inertia Force of Connecting Rod}

Fig. 11 is drawn with (8) and the result shows the graph of inertia force of connecting rod against the crankshaft angular position. The force is the multiplication of mass connecting rod with its acceleration obtained from Fig. 9, and the maximum force is $27.5 \mathrm{~N}$.

This condition occurs due to the connecting rod concentrating on the small gudgeon pin moves translatively, while the connecting rod concentrating on the large gudgeon pin moves rotatively. From Fig. 11 it can also be analyzed that the gravitation weight of the connecting rod will move fluctuatively.

\section{E. Inertia Force of Main Bearing in Horizontal Direction}

The inertial forces of the main bearing in horizontal direction is calculated by (13) and the result is drawn Fig. 12.

The graph is a pure sinusoidal because the force on the main bearing is a combination of the forces of piston and connecting rod that works following the sine curve. The inertia force in the horizontal direction for two rounds of the crankshaft is $12.5 \mathrm{~N}$ at the angles of $90^{\circ}, 450^{\circ}$, and $12.5 \mathrm{~N}$ at the angles of $270^{\circ}, 630^{\circ}$. 


\section{F. Inertia Fore of Main Bearing in Vertical Direction}

The inertia force acting on the main bearing in the vertical direction is calculated by (14), and the result is shown in Fig 13. Like the inertial forces on main bearing in the horizontal direction, this inertia force is also a combination of the inertial force of piston and connecting rods.

The maximum of inertia force is $89 \mathrm{~N}$ and occurs twice, i.e. at the angles of $0^{\circ}$ and $360^{\circ}$, respectively.

\section{G. Inertia Force due to Weight of Crankshaft System}

The inertia forces due to the weight of crankshaft system are calculated by (17). The total weight of dynamic components that work on the main bearing at the supporting point $\mathrm{Q}$ is $17.285 \mathrm{~N}$.

\section{H. Inertia Force due to Working of Crankshaft System}

Fig 14 shows the total dynamic inertia force of flywheel (red color) and crank web (blue color) which works on the main bearing and is calculated by (19). From Fig 14 it can be analyzed that the maximum inertia forces of crank web and flywheel are $-7.007 \mathrm{~N}$ and $-5.375 \mathrm{~N}$, respectively. Both of these forces have a minus sign because the crankshaft is pressed down. In one round, the working of crankshaft system produces the inertia force at the position between $100^{\circ}$ and $250^{\circ}$.

1. Vibration Responses

The vibration response due to the force is obtained from the experimental results. The trigger forces are the forces acting upon the main bearings and obtained from the sum of the numerical inertia forces calculated by (13), (14), (17) and (19).

The force is transferred to the engine block due to the contact between the bearing elements with the engine body and causes the vibration of the engine body. The responses of vibration are in the form of acceleration amplitude as the function of time.

The responses are measured in the vertical and horizontal directions, because the engine moves up and down in vertical and horizontal, left and right directions. The results are as follows:

\section{a. Vibration Responses in Time Domain (Vertical Direction)}

The results of measurement of vibration responses in the time domain (vertical direction) can be seen in Fig 15. The blue line shows the vibration response in the time domain, whereas the red line states the time required to take one round of the crank shaft.

It can be stated from Fig 15 that the dynamic inertia forces produce a response in the form of in the vertical direction. The highest amplitude of acceleration is close to $5 \mathrm{~m} / \mathrm{sec}^{2}$ and occurs in the early of second round. The responses were measured in the four rounds of crank shaft with the period of $\mathrm{T}=0.06$ seconds.

By using mathematical manipulation, the acceleration amplitudes can be integrated to determine the displacement amplitudes of vibration so that the impact of the damage caused by the dynamic engine components can be detected earlier.

The results in Fig 15 is purely the results of vibration testing before the reconstruction so that it still looks super-position signal derived from the dynamic components of the main bearing. b. Vibration Responses in Time Domain (Horizontal Direction)

The graph of acceleration amplitude of the vibration responses in time domain (horizontal direction) is depicted in Fig 16.

As in the acceleration amplitude in the vertical direction, it can be noticed from Fig 16 that the dynamic inertia forces also resulted in acceleration amplitude. The highest value is close to $3.2 \mathrm{~m} / \mathrm{sec}^{2}$, and occurred in the early of second round. Other dominant acceleration amplitudes appear in the third and fourth rounds.

The result in Fig 16 also has physical and dynamical properties similar to Fig 15 on the measuring position of the horizontal direction and pure vibration test results before reconstruction.

c. Vibration Response in Frequency Domain (Vertical Direction)

In order to determine the vibration response in revolution per minute (RPM) that can be used to analyze the damage on the main components of the main bearing, the acceleration amplitudes of the experimental results are depicted in the form of frequency domain. The results are shown in Fig 17. The results in Fig 17 illustrate that the time required by acceleration amplitudes to move one round in the frequency domain is for $900 \mathrm{RPM}$ or $15 \mathrm{~Hz}$.

The graph also shows that the highest amplitude of acceleration is near $0.0175 \mathrm{~m} / \mathrm{sec}^{2}$ and occurred at the frequency of nearly $15 \mathrm{~Hz}$. The highest amplitude of acceleration is at the frequency close to $80 \mathrm{~Hz}$. Moreover, it can be seen from the graph that the other dominant amplitudes of acceleration appear at frequencies of around $30 \mathrm{~Hz}, 45 \mathrm{~Hz}, 60 \mathrm{~Hz}$ and $100 \mathrm{~Hz}$.

In addition, the graph shows small acceleration amplitudes that are the acceleration amplitude of vibration characteristics of the physical nature of the main bearing components on the direction of the vertical measurement.

d. Vibration Response in Frequency Domain (Horizontal Direction)

Fig 18 shows the graph of the vibration responses in the frequency domain on the horizontal direction. Similar to the vertical direction, the dominant amplitudes also appear at frequencies of around $30 \mathrm{~Hz}, 45 \mathrm{~Hz}, 60 \mathrm{~Hz}$ and $100 \mathrm{~Hz}$.

Furhermore, like in the vertical direction, small acceleration amplitude can also be seen from Fig 18; however, the amplitudes are smaller than that of the vertical direction. The reason is that the inertia force working in horizontal direction is due to the main bearing only. The highest amplitude of acceleration is $0.26 \mathrm{~m} / \mathrm{sec}^{2}$ and occurs at the frequency of around $80 \mathrm{~Hz}$.

\section{CONCLUSIONS}

Based on the systematic analysis of the dynamic behavior of main bearing, the following conclusions have been made: firstly, the determination of forces working on the main bearings can be done by the numerical study and generate the dynamic inertia forces. Secondly, the dynamic inertia force that works in cycles and continuously can be used as the excitation force which triggers the vibration in engine in horizontal and vertical direction. The responses indicated that the dynamic inertia forces caused the vibration of engine. 
As a part of the ship reciprocating engine maintenance planning, in the following study, the method of analyzing is developed and employed for investigating the vibration of ship reciprocating engine which has more complicated structure and components.

\section{NOMENCLATURE}

a Distance from flywheel to supporting $\mathrm{P}$

$\mathrm{a}_{\mathrm{cg}} \quad$ Acceleration of $\mathrm{C}_{\mathrm{g}}$

$\mathrm{a}_{\mathrm{t}} \quad$ Acceleration of piston

$\mathrm{b}$ Distance from web to supporting $\mathrm{P}$

$\mathrm{C}_{\mathrm{g}} \quad$ Center of connecting rod mass

c Distance from supporting $\mathrm{P}$ to crank pin

D Diameter of crankshaft

$\mathrm{d}_{\mathrm{w}} \quad$ Diameter of pin

e Distance from supporting $\mathrm{P}$ to $\mathrm{Q}$

$\mathrm{e}_{3} \quad$ Distance from point $\mathrm{C}_{\mathrm{g}}$ to centre of force $\mathrm{F}_{3}$

$F_{d} \quad$ Inertia force of crank web and flywheel

$\mathrm{F}_{\mathrm{R} 1} \quad$ Inertia force of supporting $\mathrm{Q}$

$\mathrm{F}_{12} \quad$ Inertia force of main bearing $=\mathrm{F}_{21}$

$\mathrm{F}_{23} \quad$ Inertia force of crank pin $=\mathrm{F}_{32}$

$\mathrm{F}_{3} \quad$ Inertia force of connecting rod

$\mathrm{F}_{43} \quad$ Inertia force of piston

g Gravitation

$\mathrm{m}_{\mathrm{cr}} \quad$ Mass of connecting rod

$\mathrm{m}_{\mathrm{rg}} \quad$ Mass of flywheel

$\mathrm{m}_{\mathrm{p}} \quad$ Mass of piston

$\mathrm{m}_{\mathrm{t}} \quad$ Total mass of dynamic components

$r_{b} \quad$ Distance of joint piston and centre of crankshaft

$r_{c g} \quad$ Distance of centre of main bearing and point $C_{g}$

$r_{d} \quad$ Distance of $C_{g}$ and joint crank pin

$r_{e} \quad$ Radius of web

$r_{f} \quad$ Radius of flywheel

$r_{p e} \quad$ Radius of crank pin

$r_{2} \quad$ Length of web

$r_{3} \quad$ Length of connecting rod (Calculating from centre of joint piston to joint web)

A

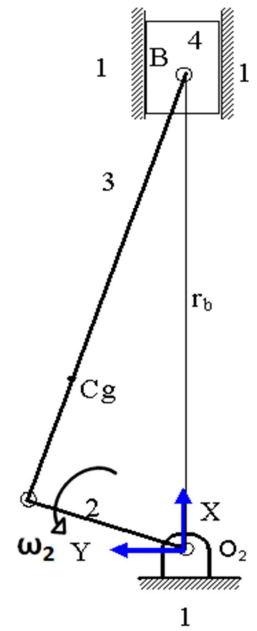

(a)

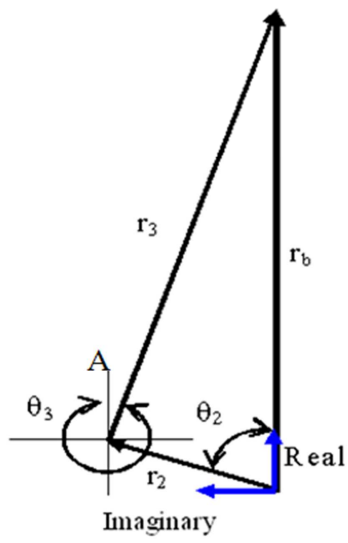

(b)

Fig. 1. Model of vertical cylinder

$\Theta_{c g} \quad$ Angle of $r_{d}$ to real axis

$\chi \quad$ Angle of vertical axis to connecting rod

[M] Mass matrix

[C] Damping matrix

[K] Stiffness matrix

$\{\mathrm{F}(\mathrm{t})\}$ Force working on main bearing

$\{\mathrm{x}(\mathrm{t})\}$ Displacement amplitude

\section{REFERENCES}

[1] Astashev V. K., Babitsky V. I., and Kolovsky M. Z., 2000, "Dynamic and control of machines", CIP Data Applied for: Die Dwtsche Bibliothek - CIP - Eiaheitsaufnahme, New York.

[2] Cho S. H., Ahn S. T., and Kim Y. H., 2002, "A simple model to estimate the impact for induced by piston slap", Journal of Sound and Vibration.

[3] Inagaki M., Kawamoto A., and Aoyama T., 2002, "Prediction of structural and kinematic coupled vibration on internal combustion engine", Research Report, Academic Society: The Japan.

[4] Tugiman, 2006, "Analisis dinamik gaya goyang motor bakar satu silinder dengan bantuan perangkat lunak Matlab," Jurnal Sistem Teknik Industri Volume 7, No. 1 Januari 2006.

[5] Chen Y., Zhiyong H., and Guangtal Z., 2009, "Balance mechanism design of single cylinder engine based on continues mass distribution of connecting rod", Journal: College of Mechanical Energy Engineering, Zhejiang University, Hangzhou 310027, China.

[6] Giancarlo G., 1950, "Vibration of structures and machines", Dipartimento di Maccanica Politecnico di Torino Carco Duca Degli Abruzzi, 2410129 Torino, Italy.

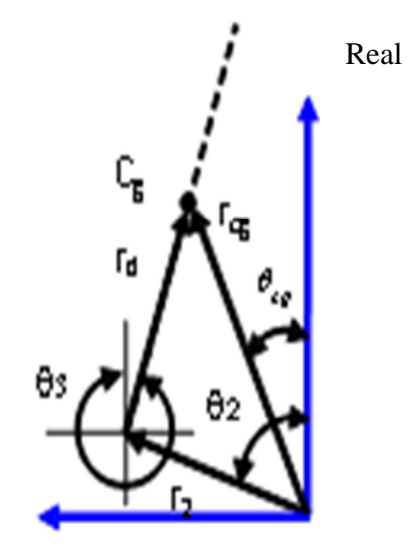

Imaginary 
(a)

(b)

Fig. 3. Model of the force working at the vertical cylinder

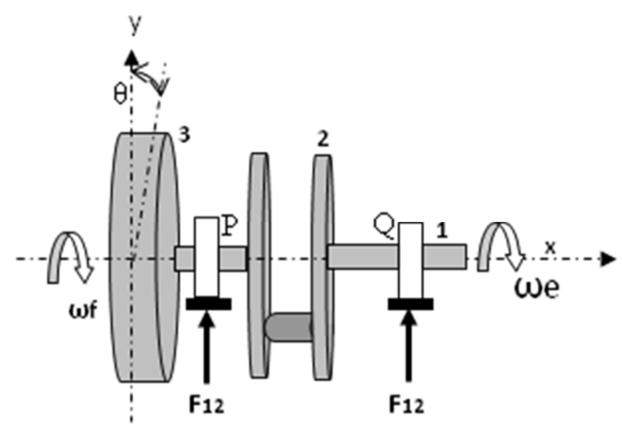

Fig. 5. Model of component of crankshaft system for calculating inertia force

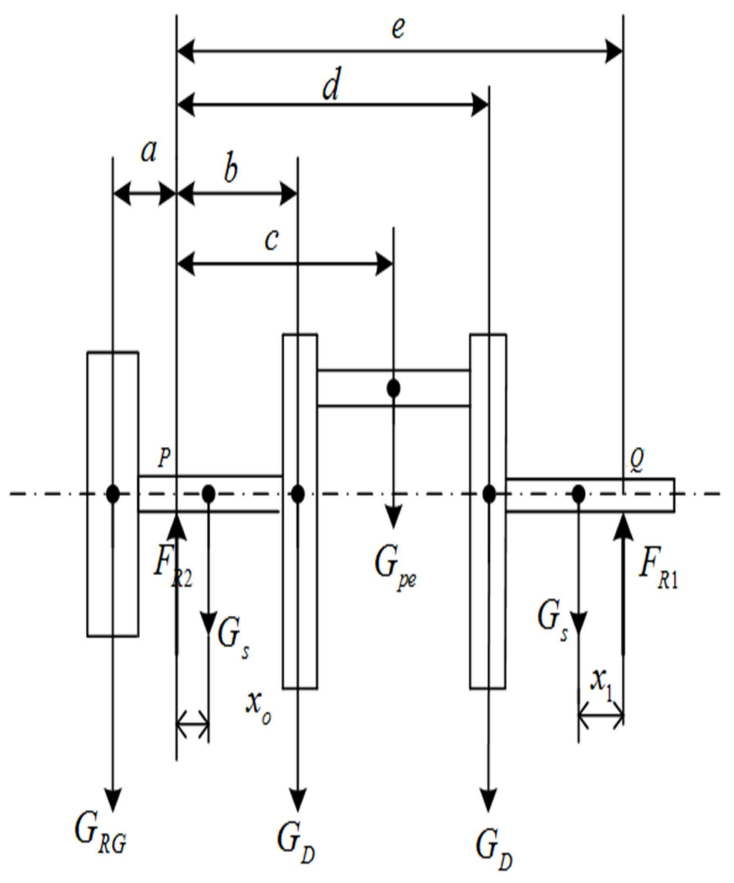

Fig. 4. Model of component of crankshaft system for calculating gravitational forces

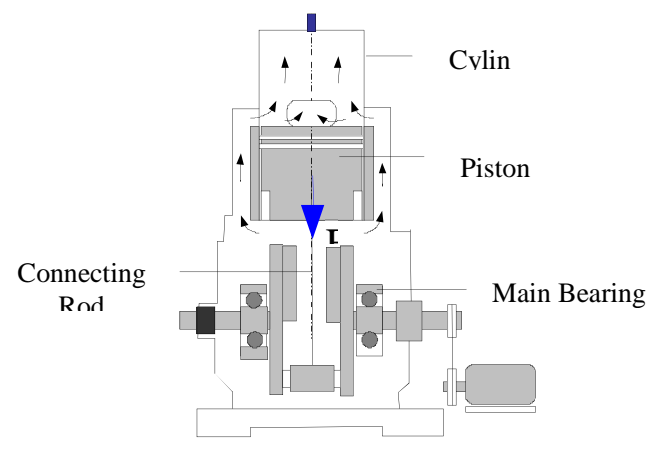

Fig. 6. The structureof two stroke engine

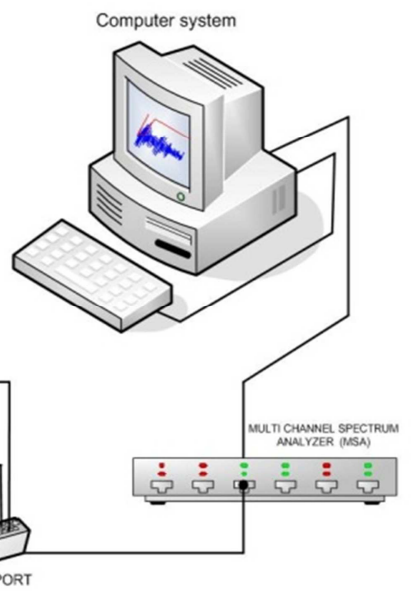

Fig. 7. Experimental setup 


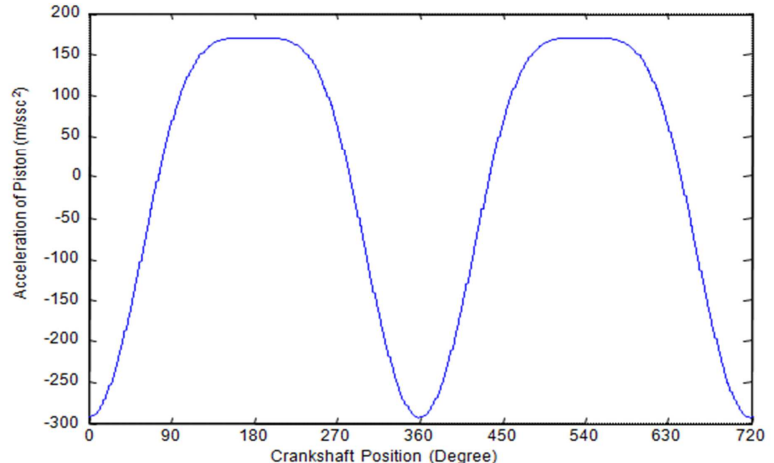

Fig. 8. A graph of piston acceleration

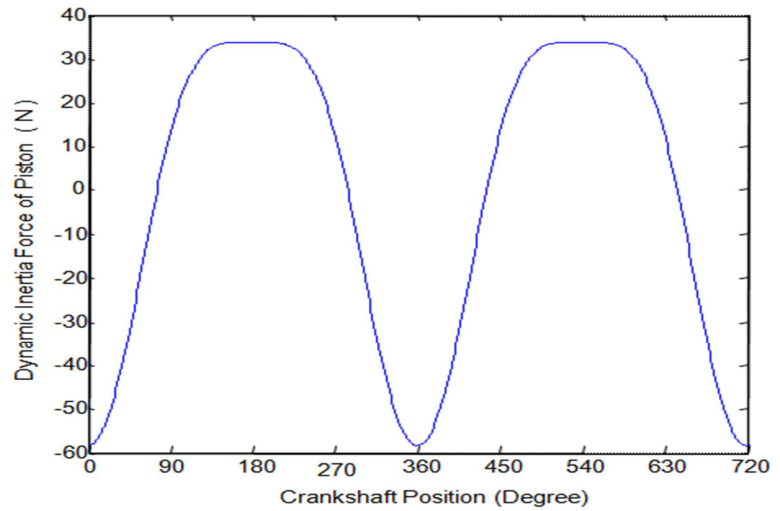

Fig. 10. A graph of inertia force of piston

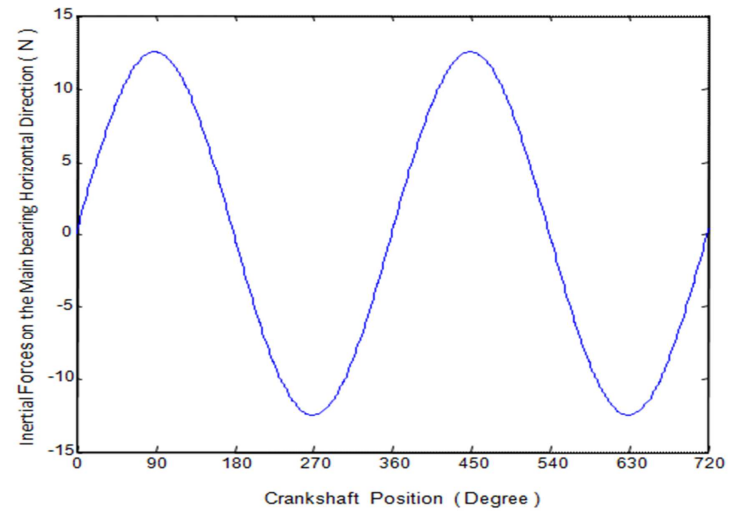

Fig. 12. A graph of the force on the main bearing in the horizontal direction

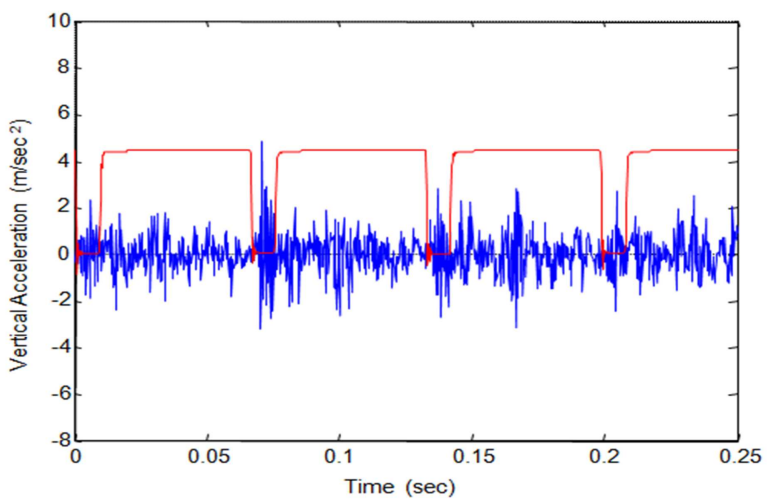

Fig. 15. A graph of acceleration amplitude in time domain (vertical direction)

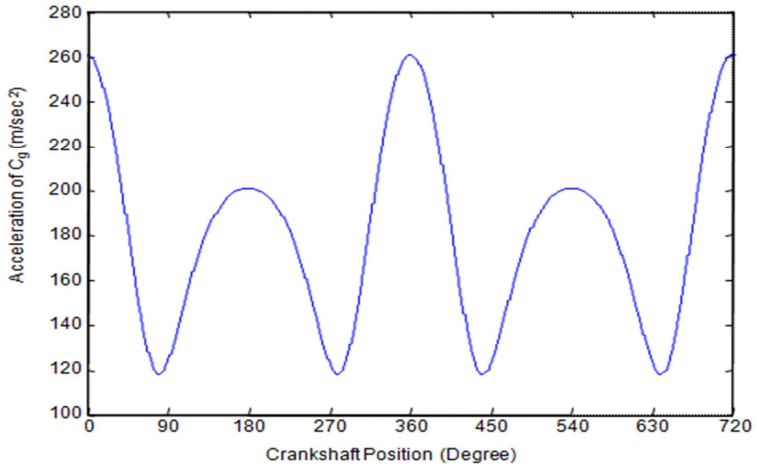

Fig. 9. A graph of connecting rod acceleration

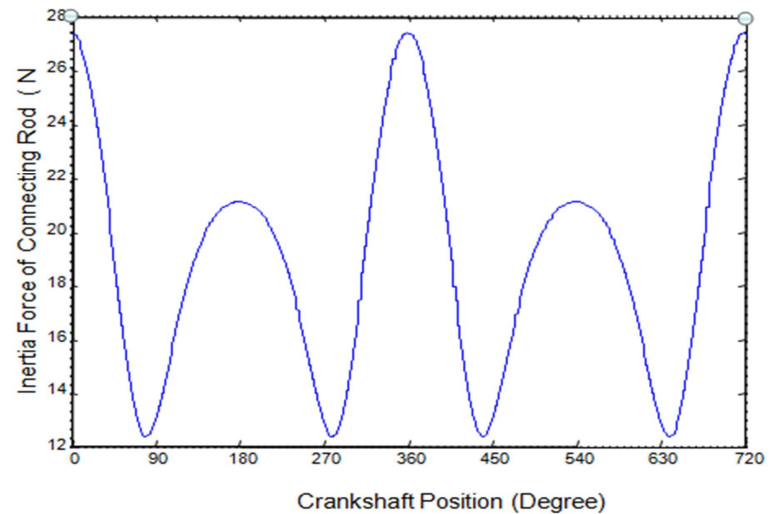

Fig. 11. A graph of inertia force of connecting rod

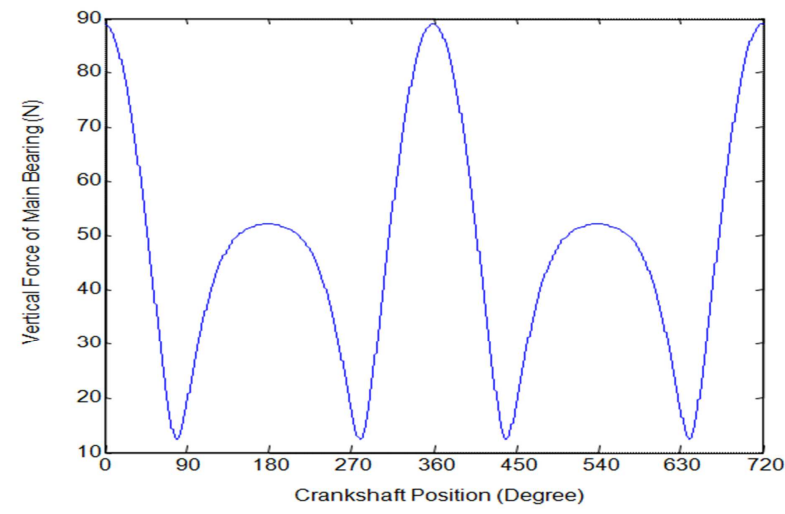

Fig. 13. A graph of the force on the main bearing in vertical direction

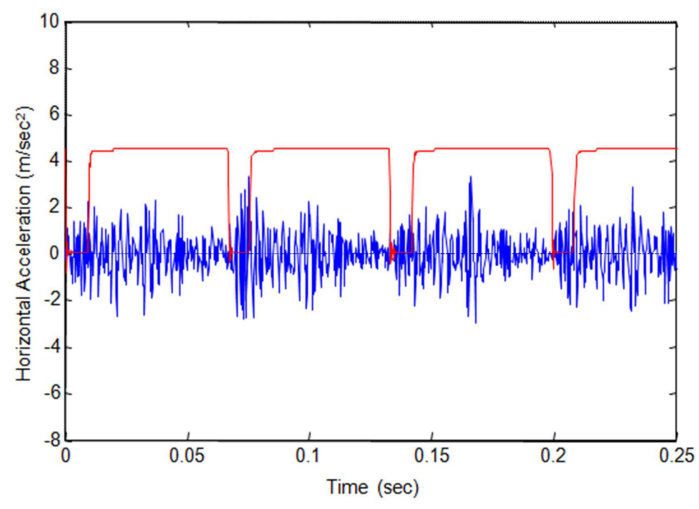

Fig. 16. A graph of acceleration amplitude in time domain (horizontal direction) 


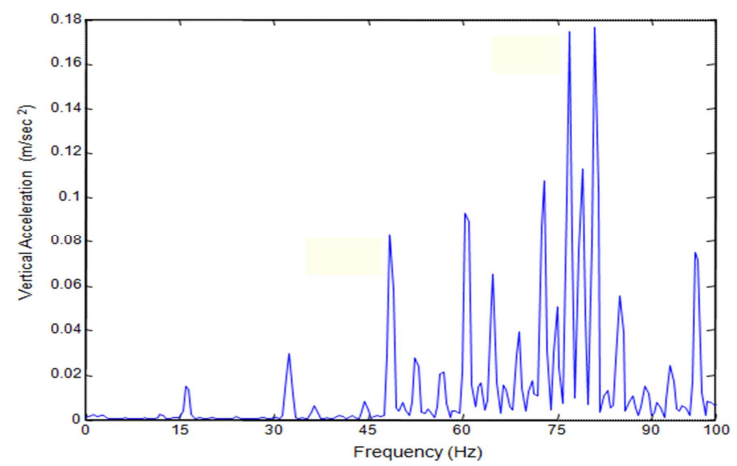

Fig. 17. A graph of acceleration amplitude in frequency domain (vertical direction)

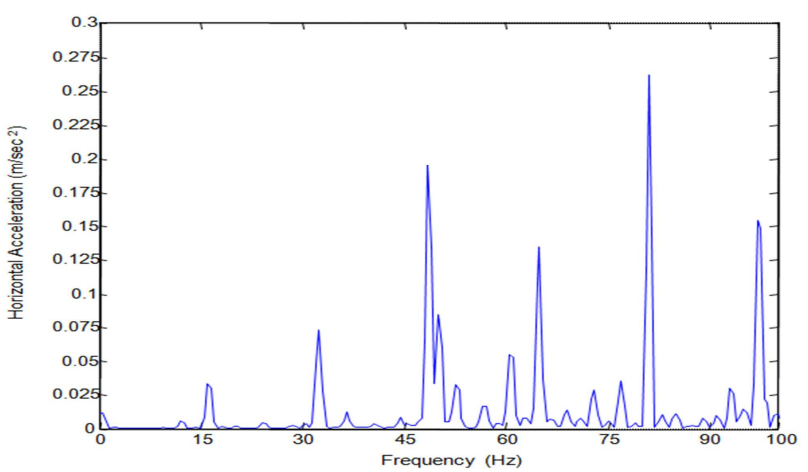

Fig. 18. A graph of acceleration amplitude in frequency domain (horizontal direction) 